\title{
Relation between the rapid evaluation method scores and the damage states of buildings
}

\author{
H. B. Ozmen \\ Pamukkale University, Civil Engineering Department, 20070, Denizli, Turkey \\ Correspondence to: H. B. Ozmen (hozmen@pau.edu.tr) \\ Received: 1 December 2012 - Published in Nat. Hazards Earth Syst. Sci. Discuss.: - \\ Revised: 8 February 2013 - Accepted: 6 March 2013 - Published: 22 March 2013
}

\begin{abstract}
A major portion of the existing Turkish building stock consists of seismically deficient buildings, like in many other earthquake-prone developing countries. For the mitigation of the damage before an earthquake, the seismic evaluation of the existing building stock is the first step. However, the great number of buildings to be evaluated is an obstacle for the detailed assessment. Rapid evaluation methods are developed to minimize the need of resources for the evaluation of the buildings in great numbers. In this study, performances of the rapid evaluation methods to estimate seismic damage are investigated by examining the correlation between the rapid evaluation method scores and the quantified damage states after the 19 May 2011 Simav (Turkey) earthquake. A total of 144 reinforced concrete buildings are carefully examined in terms of the properties of structural system, architectural layout, concrete strength, soil conditions and damage state. The correlation of rapid evaluation methods with the observed damage happened to be low. It is concluded that, if the building damage state is determined by the local brittle damages in members, the estimations with the rapid evaluation methods may diverge from the actual scene after an earthquake.
\end{abstract}

\section{Introduction}

In the past few decades, industrialization, rapid population growth and migration to the cities have brought an urgent need for new accommodation supply in Turkey, like in many developing countries. A number of buildings have been constructed with the concerns of cost and pace, disregarding compliance with the existing codes and safety. Since Turkey is an earthquake-prone country, these buildings are under serious seismic risk (Sezen et al., 2003; Ozcebe, 2004; Akkar et al., 2005; Inel et al., 2008a, Tama, 2012); unfortunately, they comprise an important portion of the existing building stock (Building Census, 2001).

Measures must be taken in order to prevent seismic damages during future earthquakes that can reach devastating levels due to the high number of deficient buildings. For the mitigation of the damage before an earthquake, the seismic evaluation of the existing building stock is the first step. However, the great number of the buildings in stock that require seismic evaluation is an obstacle. Identification of the deficient buildings with detailed seismic analyses is almost impossible due to the enormity of the needed resources of labour, time, expertise and money.

This situation directs the civil engineering profession to find simple, economical, and yet reliable enough methods to identify the safety level of structures. At this point rapid evaluation methods come into the picture (Ozcebe, 2004; Korkmaz, 2010). As the name implies, buildings can be evaluated in a rapid, economical and practical way by using these methods. They can be used to make final decisions about the buildings, to prioritize a group of buildings or to reduce the ones needing more detailed analysis.

There are many rapid evaluation methods developed for use in seismic evaluation (FEMA-154, 1988; Japan Seismic Index - Ohkubo, 1991; FEMA-310, 1998; FEMA-154, 2002; Ozcebe, 2004; Yakut, 2004; Bal et al., 2006). These various methods for the vulnerability assessment of buildings differ in expenditure and precision. The type of the method chosen depends not only on the objective of the assessment, but also on the availability of data and technology. In order to contribute this discussion and to investigate if the building scores determined by these are correlated with seismic damage, the study presented in this paper is conducted. 
The damage data collected after the 19 May 2011 Simav (Turkey) earthquake are used to examine the correlation with rapid evaluation method scores proposed previously by researchers (Ozcebe, 2004; Yakut, 2004; Bal et al., 2006). The conclusions of this study may be useful for the further development of such methods and understanding the effects of seismic events on buildings. Although this study focuses on Turkish building stock, it may resemble cases of other developing countries in earthquake-prone regions.

\section{Information about the earthquake and the region}

The properties of the ground motion, geology and seismic damages in the region (Inel et al., 2013) and damaged building data set and geotechnical properties of Simav city (Ozmen et al., 2013a) are given in some other studies in the literature. However, for the completeness of the paper it is summarized here as well.

\subsection{Characteristics of the ground motion}

The 19 May 2011 Simav earthquake was a seismic event with a magnitude of $5.7\left(M_{\mathrm{L}}\right)$, which was reported to have a normal fault mechanism. The epicentre was at the northeast of the Simav district with a distance of $13 \mathrm{~km}$ (DEMP, 2011). Unfortunately, the Simav station record, where most of the damages occurred and closest to the epicentre, was not fully obtained due to malfunction of the device. The larger one of the PGA (peak ground acceleration) value among two components was $0.118 \mathrm{~g}$ (acceleration of gravity) for the partial Simav record, experienced for E-W direction.

As the Simav record was not fully obtained, the PGA value may not be the correct one. Inel et al. (2013) have investigated the PGA values for the Simav record using the distance and PGA of the closest 20 stations to the epicentre. With simple logarithmic relation, and some attenuation relations, they concluded that expecting a PGA value between $0.138 \mathrm{~g}$ (estimation by the relation for the recorded stations) and $0.185 \mathrm{~g}$ (by Kalkan and Gulkan, 2004 attenuation relation) at Simav is reasonable with gathered information.

\subsection{Geological features of the region}

Simav is in the western Anatolian tectonic structure. The E$\mathrm{W}$ and NW-SE trending grabens with neotectonic features are Gokova, Buyuk and Kucuk Menderes, Gediz and Simav. The region is very active in terms of seismicity. Gediz-Emet, Simav and Kutahya fault zones are the main structures that cause earthquakes. Simav city is located on the active Simav Fault zone (Sengor et al., 1984; Bozkurt, 2000).

The base rock in the Simav region is metamorphic units of Menderes Massif, which are Paleozoic age schist, gneiss and marble. Other major geological units in the area are Paleocene age Egrigoz granite, Neogene age Kizilbuk formation, Early Quaternary age basalt and Quaternary age alluvium (Seyitoglu, 1997; Oygur and Erler, 2000; Mutlu, 2010).
Ozmen et al. (2013a) used the Multichannel Analysis of Surface Waves (MASW) measurements, boreholes and laboratory data to determine soil properties in the Simav county centre where the damage data are taken. Medium plastic clay (CI), silty sand (SM) and silty gravel (GM) are very common soil types in the Simav county centre. Sandy soils are also observed in several parts of the study area. The soil type of the study area is classified as B, C, and D of FEMA-368 (2001).

The groundwater depth in the study area changes between less than $2 \mathrm{~m}$ and more than $10 \mathrm{~m}$. Shear wave velocities between 180 and $360 \mathrm{~m} \mathrm{~s}^{-1}$ are encountered. In terms of liquefaction potential, the risk level changes in wide a range, between high to none in the area. However, no trace of liquefaction during the earthquake is found. Maps of the groundwater depth, shear wave velocity, liquefaction risk and soil type properties of the study area can be found at Ozmen et al. (2013a).

\section{Building set}

The damaged building set includes 144 reinforced concrete (RC) buildings which are carefully examined in terms of the properties and geometry of structural system, sizes of structural elements and infill walls at ground storey. Spacing and number of lateral and longitudinal reinforcement is checked by Ferroscan instruments on a few columns and beams. Cover concrete of a representative column in each building is stripped of in order to observe the properties of reinforcements. Architectural layout, damage conditions, concrete strength, and soil condition data of all the buildings are collected. Concrete strength is determined by concrete core samples taken from the buildings. Soil conditions are resolved as given in the part about geology.

Damage states of the buildings are quantified according to the classifications used in the European Macroseismic Scale (EMS) (Grünthal, 1998). Decisions on the damages at the member level are done according to "Quick Inspection Manual of Damaged Reinforced Concrete Buildings due to Earthquakes" (Kaminosono et al., 2002), which is in compliance with RC building damages in Turkey.

In order to have a better evaluation, the damage state steps in EMS are further classified into two. The damage states in EMS are in 5 grades, and it is modified to be in 9 with an addition of 0.5 steps. Definitions of EMS and modified EMS (used in this paper) grades are given in Table 1. The distribution of the damage grades in the building set according to modified EMS classification is given in Fig. 1.

Another important parameter about the building set may be the compressive concrete strength. As the investigated buildings are selected among damaged ones after such a moderate earthquake, concrete strengths of them are not very favourable. The values are between 3.40 and $12.00 \mathrm{MPa}$, with a mean value of $6.93 \mathrm{MPa}$ and coefficient of variation of $27.7 \%$. Ozmen et al. (2013a) may be looked at for further information. 
Table 1. The definition of EMS and modified EMS grades used in the study.

\begin{tabular}{llll}
\hline EMS & $\begin{array}{l}\text { Modified } \\
\text { EMS }\end{array}$ & $\begin{array}{l}\text { Structural } \\
\text { Damage }\end{array}$ & $\begin{array}{l}\text { Non-Structural } \\
\text { Damage }\end{array}$ \\
\hline \multirow{2}{*}{ Grade1 } & Grade1.0 & None & Slight \\
& Grade1.5 & None & Slight to Moderate \\
\hline \multirow{2}{*}{ Grade2 } & Grade2.0 & Slight & $\begin{array}{l}\text { Moderate } \\
\text { Grade2.5 }\end{array}$ \\
& Slight to Moderate & Moderate to Heavy \\
\hline \multirow{2}{*}{ Grade3 } & Grade3.0 & Moderate & Heavy \\
& Grade3.5 & Moderate to Heavy & Moderate to Heavy \\
\hline \multirow{2}{*}{ Grade4 } & Grade4.0 & Heavy & Very Heavy \\
& Grade4.5 & Heavy to Very Heavy & Partial Collapse \\
\hline \multirow{2}{*}{ Grade5 } & Grade5.0 & Collapse & - \\
\hline
\end{tabular}

\section{Rapid evaluation methods}

Rapid evaluation methods are developed for the estimation of the seismic risk based on building properties before an earthquake. When especially evaluation of a stock of buildings is the issue, seismic inspection of the buildings may be classified into three groups (Ozcebe, 2004). The first and the least detailed one is the "walk down survey", which is done only by visual inspection and finished within minutes for a building, like FEMA-154 (1998). The third and the most comprehensive one is the detailed structural analysis of the building. This may be finished in days depending on the building size and complexity and requires specialized labour. The second one is in the middle between these in the sake of the gathered information, required effort, expertise and accuracy, which may be finished in a couple of hours. Usually this also requires information on the dimensions of the building and columns in ground stories, soil conditions and lateral reinforcement in RC members to some extent. However, necessary information is much limited when compared to the third one, and the analysis process is much simpler.

The third kind of seismic evaluation for a group of buildings in limited time is generally not practical or even possible for most cases. The first one may have limited accuracy when specific buildings are considered rather than a group of buildings in a region. When the level of accuracy and required information is considered, the second type of rapid evaluation methods seems promising. Therefore Ozcebe (2004), Yakut (2004), and P25 (Bal et al., 2006), which are all second type methods, are selected to be examined in the scope of this study. These are developed by information on Turkish building stock, which is in accordance with the damage data used.

\subsection{Ozcebe (2004)}

This method is developed by a project funded by Scientific and Technical Research Council of Turkey (TUBITAK). The

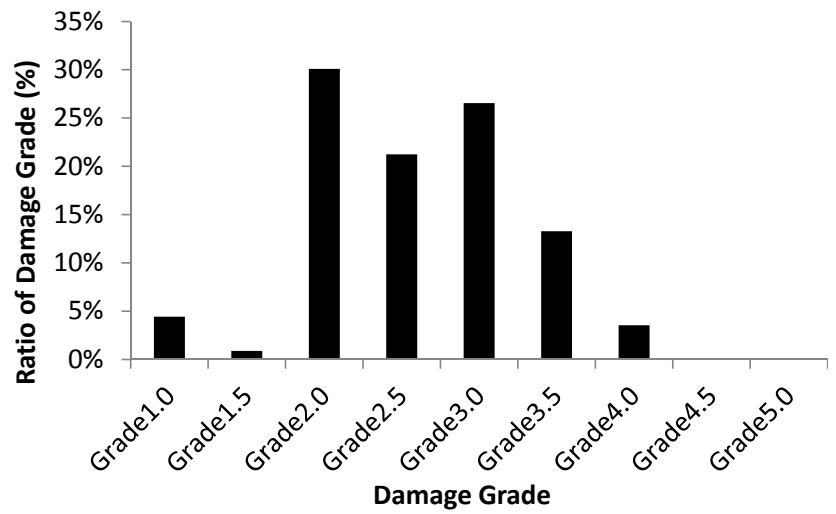

Fig. 1. The ratios of the damaged buildings according to modified EMS classification.

method is given for two performance states as immediate occupancy (IO) and life safety (LS).

The method is based on the capacity and demand indexes determined by statistical evaluations gathered from the buildings after earthquakes. If the capacity indexes for the IO and LS levels are both greater than demand indexes, the structure is assumed as safe. If they are both lower than demand indexes, the structure is unsafe; otherwise it is in grey zone.

As the other methods are for LS, to have a comparison LS part of it is considered. Since the other two methods give oneparameter results, for similarity the capacity index minus the demand index is employed to reduce the results to a single parameter. As value of this parameter increases, so does the safety level of the building. The ratio of the capacity over demand index thought to be more suitable at first, but as the indexes may take positive or negative values the results may be mathematically unstable.

The capacity index depends on the moment of inertia of column and shear walls, effective area of columns, shear walls and infill walls at ground storey based on their larger dimension, continuity of the load carrying frames, difference between ground and upper storey height, overhang amount at the building and number of stories.

The demand index depends on the soil conditions based on shear wave velocity, distance to the fault and number of stories in the building.

Therefore, the required data are the dimensions of the columns, shear wall and infill walls at the ground storey, continuity of the frames, ground and upper storey height, area of overhang portions, shear wave velocity, distance to the fault and number of stories.

\subsection{Yakut (2004)}

Yakut (2004) has developed a preliminary procedure to assess the probable seismic performance of existing reinforced concrete buildings. The procedure has been tested and calibrated based on the data compiled from damage surveys 
conducted after the earthquakes that occurred within the last decades in Turkey. The method is based on calculation of a capacity index by using column and shear wall dimensions at the ground storey and compressive strength of the concrete. Member area is summed up by multiplying a factor that depends on the orientation of the longer dimension. The base shear capacity calculated from these values is modified by a factor depending on the area of infill walls. Consequently, the base shear capacity of the building that includes the shear capacity of infill walls is determined.

This shear capacity is divided by the estimated shear demand of the building to obtain basic capacity index (BCPI). The procedure suggests use of seismic codes for the calculation of shear demand. BCPI is the value for the regular buildings. For irregularities, it is multiplied by factors less than unity. The aforementioned irregularities are soft storey, short column, torsional irregularity due to plan shape and overhangs, and discontinuity of the structural members in plan and in vertical direction.

In addition, besides irregularity factor, BCPI is multiplied by a factor for construction quality. It is given for three classes as good, moderate and bad based on the value of irregularity factor. For good quality buildings, it is given as unity and for the others less than unity.

After modifying the BCPI for irregularity and construction quality factors, capacity index (CPI) is determined. As the CPI increases, so does the safety level of the building.

The required data are the dimensions of the columns, shear wall and infill walls at the ground storey, compressive strength of the concrete, information about continuity of the members in plan and in vertical direction, soft storey, irregularity due to in plan non-uniformity and overhangs, construction quality, number of stories and soil class for determination of code shear demand.

\section{$4.3 \quad$ P25 (2006)}

The method is the most detailed and comprehensive one with the highest requirement of knowledge among the methods mentioned here. It is developed to identify the buildings that have a probability of collapsing during earthquakes. The method is applied to $323 \mathrm{RC}$ buildings with different damage states, located in different soil conditions and subjected to various seismic actions (Bal et al., 2006).

Firstly, a $\mathrm{P}_{0}$ score is calculated using the dimensions of columns, shear walls and infill walls at critical storey and building height. $\mathrm{P}_{0}$ score depends on the total rigidity and strength of the RC and infill wall members divided by a factor for building height. Then $\mathrm{P}_{0}$ score is modified using 14 different "f factors" to get $\mathrm{P}_{1}$ score.

The "f factors" include corrections for torsional irregularity, slab discontinuity, discontinuity of elements in vertical direction, mass irregularity, corrosion of reinforcement, heavy cladding, presence of mezzanine, different levels of storey slabs and partial basement floor, concrete strength, weak-column strong-beam, lateral reinforcement spacing, soil type, foundation type and foundation depth.

After calculation of $\mathrm{P}_{1}$ score, which is called basic structural score, 6 more $\mathrm{P}$ scores, having values between 0 and 100 , for different irregularity and deficiencies are also determined. $\mathrm{P}_{2}$ score is for presence of short column and based on the length and amount of short columns in the building. $\mathrm{P}_{3}$ score is for weak and soft storey and depends on the differences of rigidity and effective area of load carrying elements between stories. $\mathrm{P}_{4}$ score is for the presence of overhangs and continuity of frames in the building. $\mathrm{P}_{5}$ score is for pounding and given in tabulated form for the different cases ranging between 10 and $100 . \mathrm{P}_{6}$ score is for the liquefaction effects and depends on the depth of groundwater level and liquefaction risk. Finally, $\mathrm{P}_{7}$ is the soil-bearing capacity failure score depending on the soil type and the depth of groundwater level.

All the $\mathrm{P}$ scores are averaged with corresponding importance factors, and $\mathrm{P}_{\mathrm{w}}$, the weighted mean score, is calculated. Depending on this $\mathrm{P}_{\mathrm{w}}$ score, a $\beta$ factor is determined. In addition, an $\alpha$ factor is also determined depending on the importance of the considered building, expected ground acceleration and topography of the site. Then the final $\mathrm{P}$ score is calculated according to Eq. (1).

$\mathrm{P}=\alpha \beta \mathrm{P}_{\min }$.

Buildings with $\mathrm{P}$ scores less than 25 are regarded as certain candidates for collapse. Buildings with P scores from 26 to 34 should be further investigated, and P scores equal to 35 or more indicate safety against total collapse.

\section{Correlation between damage score and rapid evaluation methods}

The correlation of the estimations by the rapid evaluation methods and the damage after the earthquake may be a point of subject. The relationships between the damage and rapid evaluation method scores are given in Fig. 2.

The damage states of the buildings seem to be decreasing with increasing scores as expected but with low correlation factors. The maximum correlation factor is for Ozcebe (2004) method with a value of 0.28 . The others are 0.12 and 0.11 for Yakut (2004) and P25 methods, respectively. The scatters from the trend lines are considerable for all, and the outcome may not be seen as satisfactory.

\subsection{Discussions on the reason of low correlation}

Low correlation is somewhat unexpected, because all of these methods are developed and calibrated using past earthquake data and suggested to be usable for estimation of seismic behaviour of buildings in literature.

It is believed that the reason for that are the local (member level) damages in the buildings. As the damage states are determined according to the cracks, whether the reasons 

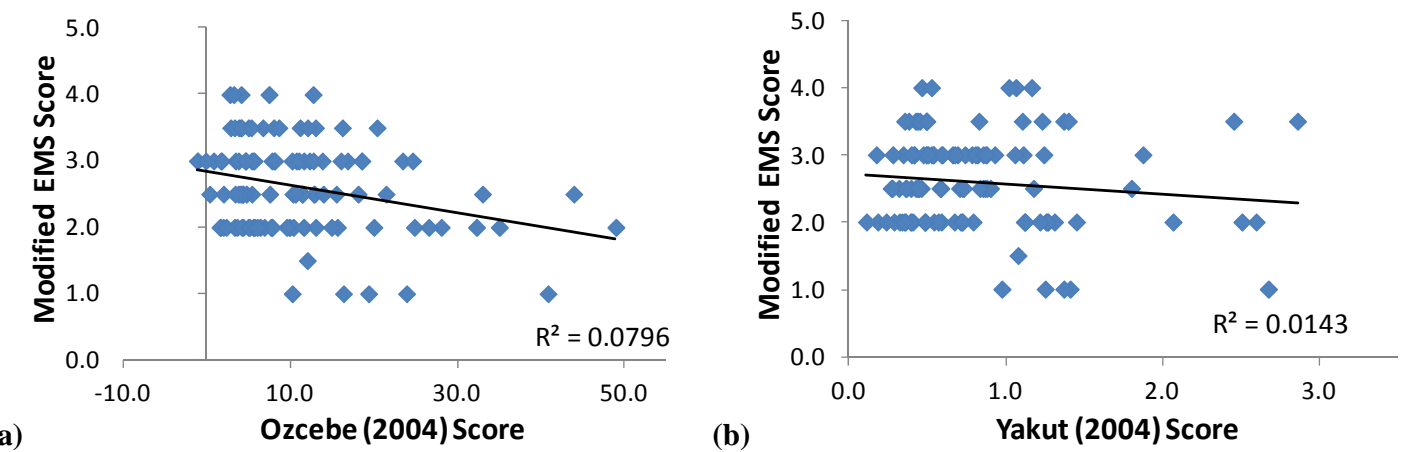

(b)

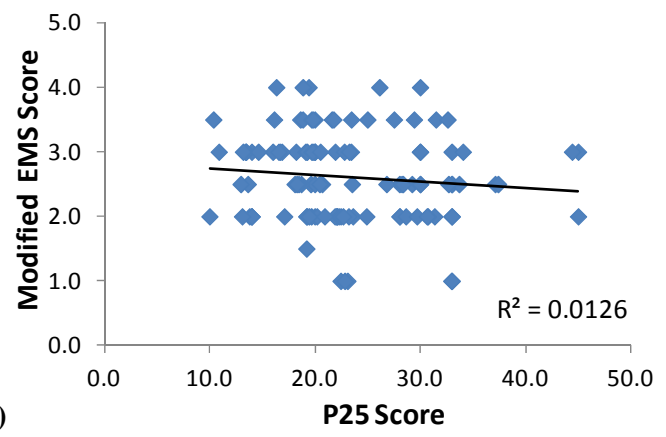

Fig. 2. Relation between observed damage and considered rapid evaluation method scores: (a) Ozcebe (2004), (b) Yakut (2004), and (c) P25 method.

for them are related with the global properties is very important. The global properties of the buildings accounted for in the rapid evaluation methods can be effective on the behaviour, if the buildings behave as a system. The single way of RC buildings behaving as a system is the flexure. On the contrary, in shear behaviour members may fail individually independent of global building properties. When the concrete strength and lateral reinforcement amount in the building set are considered, the members are in the grey area between shear and flexure.

Additionally, the damages due to improper construction like reinforcement detailing mistakes, cold joints, and foreign substances in concrete cannot be identified considering general building characteristics. All of the above-mentioned reasons of damages are reported in the Simav region (Inel et al., 2013).

Since the earthquake was not very devastating, the damage levels of the buildings after the Simav earthquake seem to be in various ranges. If the earthquake had been a larger and destructive one, it would destroy or heavily damage all the deficient buildings, making them in the same damage grade. Since the better ones are more likely to behave in flexure, the global building properties will be more representative regarding the damage grade. Under those circumstances, it is believed that better estimations may be achieved by the rapid evaluation methods.

Use of these methods in extremely deficient buildings, like the buildings with extensive lap splice length insufficiency or joint failures, may lead to very erroneous estimations. One extreme example of this is the collapse of the Gedikbulak Primary School after the 23 October 2011 Ercis (Turkey) earthquake. Even if the three story school building had shear-walls more than $0.8 \%$ and $1.14 \%$ of floor area in two principal directions, has experienced catastrophic collapse. The collapse of that type of a building is not expected as many resembling ones have been evaluated before (Inel et al., 2008b). The reason for the collapse is thought to be insufficient lap splice lengths and joint failures (Ozmen et al., 2013b). None of the rapid evaluation methods can predict that a building with that much shear wall could experience collapse. This emphasizes the importance of the some local factors that are hard to be considered in these methods.

\subsection{Detail level and damage correlation relation}

Although all of the correlation factors between rapid evaluation methods and observed damage may be considered as low, it is interesting to see that the one with the least level of detail has the best correlation. If they are ranked in descending detail level, the one with the highest requirement of information is P25 method. Yakut (2004) and Ozcebe (2004) methods follow, respectively. Nevertheless, the correlation order is quite the opposite. Even concrete strength and amount of lateral reinforcement are not considered in Ozcebe (2004) method. It is the most statistically based one and also called "statistical approach" (Ozcebe, 2004). One may consider if the simple statistical approaches handle the mentioned uncertainties better. 

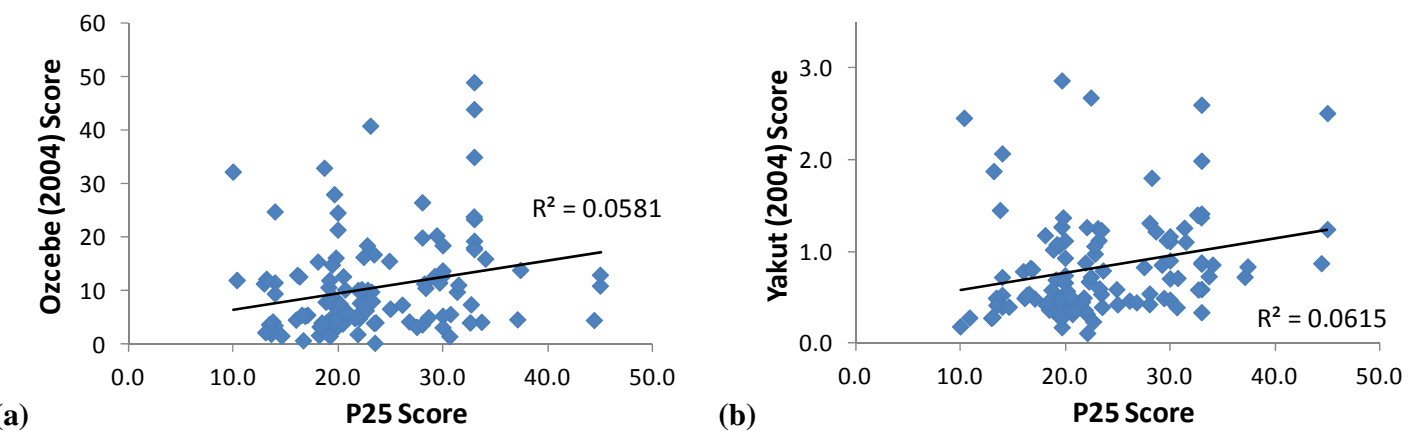

(a)

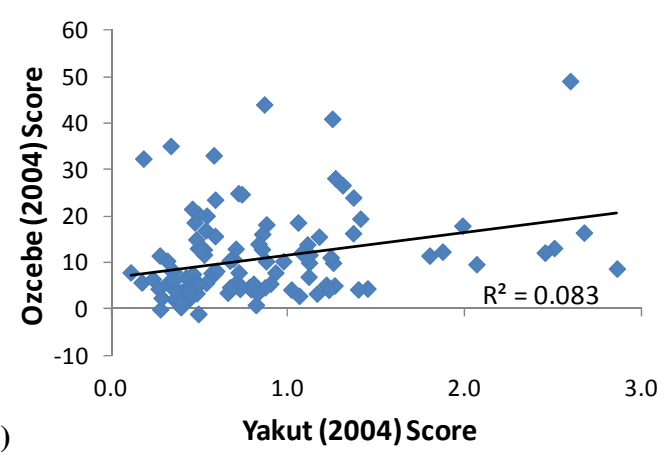

(c)

s: (a) P25 and Ozcebe (2004), (b) P25 and Yakut (2004), and (c) Yakut (2004) Fig. 3. Relation betwee
and Ozcebe (2004).

The P25 (Bal et al., 2006) method accounts for many points that are not or less considered in the other methods, like the depth of the groundwater level, liquefaction risk, soil bearing capacity, presence of partial basement floor and topography. Therefore focus on the structural properties somehow scatters. As an earthquake becomes larger and more devastating, the aforementioned properties become more important. Otherwise they do not much affect the damage and cracking in the building that defines the damage state. Therefore, if such limited data may be generalized, it seems, if the problem is the estimation of the damage state for moderate earthquakes, rapid evaluation methods with extensive parameters may not be the most suitable identifier.

\section{Comparison of the rapid evaluation methods}

The second subject of concern may be how the considered rapid evaluation methods are related, if the values of the scores of the methods are in accordance with each other. In Fig. 3, the correlations between the couples of the rapid evaluation methods are given. The correlation factors again happen to be low, between 0.24 and 0.29 .

The low correlation may be expected when the differences in the methods are considered. For example, the concrete strength is crucial for the Yakut (2004) as it directly affects the capacity index. However, for the P25 method it only affects one of the P scores among seven, as being one of the other 14 "f factors" that affect the same P score. In
Ozcebe (2004) method, it is not considered at all. Same is also true for the amount of lateral reinforcement. It is not considered in Yakut (2004) and Ozcebe (2004) methods, but it is a parameter in P25 method like concrete strength. Even if they all have the same goal - rapid assessment of RC buildings - they handle the problem very differently. Many other important divergences may be found between these methods.

Although the correlation factors are low, when the figures are examined carefully, they do not look to be much unrelated, except some points that are very different from the trend lines. In all figures, correlation factors are greatly reduced by these points. These figures belong to the building properties, which are handled differently in the methods.

The Ozcebe (2004) and Yakut (2004) methods are the ones which have the greatest similarities with the highest correlation. That is a very expected result as they both greatly depend on the properties of the load carrying system of the building and irregularities. However, in P25 method the lowest $\mathrm{P}$ factor is very important and it is the basis for the final score. The lowest $\mathrm{P}$ score may be due to liquefaction or soil bearing capacity, and the final score may have little to do with the structural properties.

\section{Summary and conclusions}

A major portion of the existing Turkish building stock consists of seismically deficient buildings, like in many earthquake-prone developing countries. For the mitigation of 
the damage before an earthquake, the evaluation of the existing building stock is the first step. The great number of buildings to be evaluated is an obstacle for the seismic assessment of all buildings in stock. Rapid evaluation methods are developed to overcome this problem. In this study, the correlation between the rapid evaluation method scores and the damages after the 19 May 2011 Simav (Turkey) earthquake is evaluated.

A total of $144 \mathrm{RC}$ buildings in Simav city are carefully examined for the properties of structural system architectural layout, damage state, concrete strength and soil conditions. Seismic performances of these buildings are estimated with rapid evaluation methods. The findings are summarized in the following:

- The damage of the buildings seems to be decreasing with increasing rapid evaluation method scores as expected but with low correlation factors. The maximum correlation factor is for Ozcebe (2004) method with a value of 0.28 . The others are 0.12 and 0.11 for Yakut (2004) and P25 methods, respectively. The scatters from the trend lines are considerable for all of them, and the outcome may not be seen as satisfactory. The possible reason for that may be the local (member level) damages in the buildings.

- It seems that as the local brittle damages in the members increase and determine the building damage state, the estimations with the rapid evaluation methods may diverge from the actual scene after an earthquake. Additionally, if the magnitude of the earthquake is low, the building damage states spread in a wide range. This also complicates the estimation of the building damage with the rapid evaluation methods.

- Due to the assumption of global behaviour in the nature of rapid evaluation methods, use of them for the buildings with excessive deficiencies, like extensive lap splice length insufficiency or joint failure risk, may lead to very erroneous estimations.

- The compliance between the rapid evaluation methods is also investigated. The correlation factors for couples of them are also low, between 0.24 and 0.29 . The low correlation may be expected when the differences in the methods are considered. Even if they all have the same goal - rapid assessment of buildings - they all handle the problem differently.

Of course the submitted data are very limited and more investigation is needed to come to solid conclusions. As the scope of the study and the lower magnitude of the Simav earthquake are considered, the outcomes of this study do not suggest which of these methods has greater accuracy.

It should be clarified that this study does not imply the rapid evaluation methods are useless or fail to estimate seismic damage accurately. On the contrary, it is believed that these methods are important steps towards the estimation of damages for stock of buildings in a practical way. The evaluation of the strong and weak points of the rapid evaluation methods and when to use them correctly are among the aims of this paper. This way it has aimed to contribute to the development of these methods.

Acknowledgements. The author acknowledges that the building data used in this paper are taken from the study by Inel et al. (2011) after the 2011 Simav earthquake, which is summarized in Ozmen et al. (2013a). The study by Inel et al. (2011) is financially supported by Republic of Turkey Prime Ministry Disaster and Emergency Management Presidency. The author thanks the supporting institution and all the contributors of the study.

Edited by: O. Katz

Reviewed by: three anonymous referees

\section{References}

Akkar, S., Sucuoglu, H., and Yakut, A.: Displacement based fragility functions for low- and mid-rise ordinary concrete buildings, Earthq. Spectra, 21, 901-927, 2005.

Bal, İ. E., Tezcan, S. S., and Gülay, F. G.: Advanced applications of the p25 scoring method for the rapid assessment of RC buildings, in: Proceedings of the 1st European Conference on Earthquake Engineering and Seismology, 3-8 September, Paper no.: 067, 2006.

Building census 2000, State Institute of Statics Prime Ministry of Turkey, Ankara, Turkey, 2001.

Bozkurt, E.: Timing of extension on the Büyük Menderes Graben, western Turkey, and its tectonic implications, tectonics and magmatism in Turkey and the surrounding area, Geological Society, London, Geological Society Special Publication no. 173, 385403, 2000.

DEMP (Disaster and Emergency Management Presidency): Monthly earthquake report, Ankara, 20 pp., May 2011 (in Turkish).

FEMA-154 rapid visual evaluation of buildings for potential seismic hazards: a handbook, Federal Emergency Management Agency, Washington, 1988.

FEMA-154 rapid visual screening of buildings for potential seismic hazards: a handbook, Federal Emergency Management Agency, Washington, 2002.

FEMA-310 handbook for the seismic evaluation of buildings a prestandard, American Society of Civil Engineers for the Federal Emergency Management Agency, Washington, 1998.

FEMA-368 NEHPR-recommended provisions for seismic regulations for new buildings, Buildings Seismic Safety Council, Washington, 2001.

Grünthal, G.: European macroceismic scale 1998 (EMS98), Cahiers du Centre Européen de Géodynamique et de Séismologie, Luxembourg, 15, 99 pp, 1998. 
Inel, M., Bilgin, H., and Ozmen, H. B.: Performance of mid-rise reinforced concrete buildings during recent earthquakes in Turkey, Tek. Dergi, 19, 4319-4331, 2008a.

Inel, M., Bilgin, H., and Ozmen, H. B.: Seismic capacity evaluation of school buildings in Turkey, Proceedings of the ICE - Structures and Buildings, 161, 147-159, 2008b.

Inel, M., Un, H., Ozmen, H. B., Akyol, E., Cayci, B. T., and Ozcan, G.: Investigation of the feasibility of retrofitting the moderately damaged buildings in Simav county and surroundings, Report, Denizli, 2011.

Inel, M., Ozmen, H. B., and Akyol, E.: Observations on the building damages after 19 May 2011 Simav (Turkey) earthquake, B. Earthq. Eng., 11, 255-283, 2013.

Kalkan, E. and Gulkan, P.: Site-dependent spectra derived from ground motion records in Turkey, Earthq. Spectra, 20, 11111138, 2004

Kaminosono, T., Kumazawa, F., and Nakano, Y.: Quick inspection manual for damaged reinforced concrete buildings due to earthquakes (based on the disaster of 1999 Kocaeli earthquake in Turkey), Tokyo, 2002.

Korkmaz, K. A.: Integrated seismic hazard evaluation and disaster management approach for Turkey, Environmental Earth Sciences, 61, 467-476, 2010.

Mutlu, M.: Arsenic Pollution and Health Risk Assessment in the Groundwater of Simav Plain, M.S. thesis, Dokuz Eylul University, İzmir, 2010.

Ohkubo, M.: Current Japanese system on seismic capacity and retrofit techniques for existing reinforced concrete buildings and post-earthquake damage inspection and restoration techniques, Report No. SSRP-91/02, Department of Applied Mechanics and Engineering Sciences, University of California, San Diego, 1991.
Oygur, V. and Erler, A.: Metallogeny of the Simav graben (InnerWestern Anatolia), Geological Bulletin of Turkey, 43, 7-19, 2000.

Ozcebe, G.: Development of methods for the assessment of seismic safety, Report No.: TUBITAK ICTAG YMAU I574, Ankara, 2004 (in Turkish).

Ozmen, H. B., Inel, M., Akyol, E., Cayci, B. T., and Un, H.: Evaluations on the damages after 19 May 2011 Simav (Turkey) earthquake, Nat. Hazards, in review, 2013a.

Ozmen, H. B., Inel, M., and Cayci, B. T.: Engineering implications of the damages after 2011 Van Earthquakes, Earthquakes \& Structures, in review, 2013b.

Sengor, A. M. C., Satir, M., and Akkok, R.: Timing of tectonic events in the Menderes massif, Western Turkey: Implications for tectonic evaluation and evidence for Pan-African basement in Turkey, Tectonics, 3, 693-707, 1984.

Seyitoglu, G.: The Simav Graben: an example of young E-W trending structures in the late Cenozoic Extensional system of western Turkey, Turk. J. Earth. Sci., 6, 135-141, 1997.

Sezen, H., Whittaker, A., Elwood, K. J., and Mosalam, K. M.: Performance of Reinforced Concrete Building During the August 17 1999 Kocaeli, Turkey Earthquake, and Seismic Design and Construction Practice in Turkey, Eng. Struct., 25, 103-114, 2003.

Tama, Y. S.: Structural damages observed in state buildings after Simav/Turkey earthquake occurred on 19 May 2011, Nat. Hazards Earth Syst. Sci., 12, 2709-2718, doi:10.5194/nhess-122709-2012, 2012.

Yakut, A.: Preliminary seismic assessment procedure for existing RC buildings, Eng. Struct., 26, 1447-1461, 2004. 